\title{
Importance of Overweight in Studies of Left Ventricular Hypertrophy and Diastolic Function in Mild Systemic Hypertension
}

\author{
Brent Egan, MD, M. Andrew Fitzpatrick, MD, Jack Juni, MD, Andrew J. Buda, MD, \\ and Andrew Zweifler, MD
}

The relations of Metropolitan Life Insurance Co. Relative Weight values and blood pressure (BP) to minimal forearm vascular redistance, ventricular septal and posterior wall thiclaness, left ventuicular (LV) mass index and candliac diastolic function were ascessed in 31 men, $37 \pm 2$ (mean \pm standard error of the mean) years of age. Iighteen patients with untreated mild hypertension were compared with 13 nomotensive control subjects of similar age and weight. The hypertensives had higher clinic (137 $\pm 3 / 96 \pm 2$ vs $121 \pm 4 / 81 \pm 3 \mathrm{~mm} \mathrm{Hg}$, p $<0.001 /<0.001)$ and home $(p<0.001)$ BP. Desplte higher BP, the hypertensives did not have significanthy greater values than normotensives, respectivety, for minimal forearm vascular resistance $(2.20 \pm 0.12$ vs $2.04 \pm 0.11 \mathrm{U})$, ventricular septal (9.9 \pm 0.5 vs $10.2 \pm 0.3 \mathrm{~mm}$ ) and posterior wall thickness (10.2 \pm 0.4 vs $10.0 \pm 0.3 \mathrm{~mm}$ ) or LV mass index (106 \pm 6 vs $\left.107 \pm 6 \mathrm{~g} / \mathrm{m}^{2}\right)$. Furthermore, diastolic peak filling rate, an index of LV diastolic function, was virtually identical in the 2 groups (2.71 \pm 0.14 vs $2.69 \pm 0.07$ liters/s, difference not significant). Correlates of peak filling rate inchuded relative weight $(r=-0.62, p<0.001)$, posterior wall thickness $(r=-0.51, p<0.01)$ and age $(r=-0.45, p<0.05)$. Relative weight also correlated significanty with posterior wall $(r=0.59$, $p$ $<0.005)$, ventricular septal $(r=0.47, p<0.005)$ and LV mass index $(r=0.38, p<0.05)$. Athough clinic systolic BP correlated directly with posterior wall thickness $(r=0.45, p<0.05)$, neither systolic mor diastelic BP in the clinic or at home correlated aignificanty with peak filling rate $(r=-0.26$ to +0.02, difference not significant).

The results suggest that relative weight is an important determinant of diastolic function and LV dimensions. These findings highlight the imporlance of controlling for weight in comparative studies of cardiovascular stucture and function.

(Am J Cardiol 1989;64:752-755)

From the Department of Internal Medicine, Divisions of Hypertension, Nuclear Medicine and Cardiology, the University of Michigan Medical Center, Ann Arbor, Michigan. Manuscript received May 2, 1989; revised manuscript received and accepted June 30, 1989.

Address for reprints: Brent Egan, MD, Medical College of Wisconsin, Division of Cardiology, 8700 West Wisconsin Avenue, Milwaukee, Wisconsin 53226.
$\mathrm{M}$ ost untreated patients with mild hypertension do not experience complications over a mean follow-up period of 5 years. ${ }^{1}$ In fact, most patients with mild hypertension and minimal funduscopic change may die from diseases unrelated to hypertension. ${ }^{2}$ In an effort to more selectively target intervention, extensive efforts have been directed toward identifying evidence of cardiovascular injury that increases the probability of future complications. Funduscopic, ${ }^{2}$ electrocardiographic ${ }^{3}$ and echocardiographic ${ }^{4,5}$ changes in hypertensive patients are examples of abnormalities that predict a higher incidence of subsequent clinical events. Additional subclinical abnormalities identified in the mild hypertensive state include reduced maximal vasodilator capacity 6,7 and decreased cardiac compliance. ${ }^{8-10}$ The identification of impaired diastolic function, which may precede abnormalities in left ventricular (LV) wall thickness, systolic function or both, ${ }^{10-12}$ offers an opportunity for very early detection of a potentially high risk subgroup.

One confounding variable in assessing structural and functional cardiovascular changes in hypertensive patients is weight. Overweight is a significant risk factor for hypertension. ${ }^{13}$ Hypertensive patients are generally heavier than normotensive control subjects. Furthermore, overweight is an independent risk factor for cardiovascular disease. ${ }^{14}$ Overweight may induce cardiovascular changes ${ }^{15}$ that are possible harbingers of later cardiovascular problems. Consequently, evidence of cardiovascular injury in mildly hypertensive patients compared with normotensive control subjects may partially reflect weight differences rather than disparities only of blood pressure (BP). This study determines if previously noted abnormalities of cardiovascular structure and function in hypertensives persist when patients are compared with normotensive control subjects of similar age and weight.

\section{METHODS}

Patients: All hypertensive patients were untreated for a minimum of 6 months. The exception was 1 patient who went without therapy for 1 month. Patients had a BP > $140 \mathrm{~mm} \mathrm{Hg}$ systolic or $90 \mathrm{~mm} \mathrm{Hg}$ diastolic, or both, on $\geq 2$ consecutive clinic visits preceding the study. The normal volunteers had no prior history of hypertension and had clinic BP values $<140 / 90 \mathrm{~mm}$ Hg. All subjects provided a history and underwent physical and laboratory examinations to exclude the presence of medical problems, high BP excepted. 
Measurements: Height and weight were measured conventionally. The Metropolitan Life Insurance Co. Relative Weight values were used in the calculations. ${ }^{16}$ BP during casual sitting was measured in triplicate. The mean of the second and third readings was used to determine systolic and diastolic BP values. Self-determined home BP was obtained twice daily by patients and normal volunteers in the week before the study. Maximal forearm vasodilator capacity in response to 10 minutes of ischemic exercise was assessed by venous occlusion plethysmography. ${ }^{7}$ Minimal forearm vascular resistance was calculated as mean BP divided by maximal forearm blood flow.

LV internal diastolic dimension, ventricular septal and posterior wall thickness were measured from 2-dimensional $\mathbf{M}$-mode echocardiograms as previously described. ${ }^{17}$ The M-mode beam was set to transect the left ventricle just distal to the inferior edge of the mitral valve leaflets during diastole. LV muscle mass was calculated using the Penn convention. ${ }^{18}$

LV diastolic function was determined as peak LV filling rate. Data were obtained by electrocardiographically gated radionuclide ventriculograms. The results were analyzed by forward gating of the time activity curves as described previously. ${ }^{19}$

Protocol: Subjects arriving at the Clinical Research Center had their BP measured in triplicate. In the next 4 hours, the volunteers underwent echocardiography, radionuclide ventriculography and plethysmography.

Data analysis: Data for the hypertensive patients and normotensive control subjects are reported as mean \pm standard error of the mean. Differences between the 2 groups for the measured and calculated variables were assessed with the Student $t$ test. Pearson correlation coefficients ( $r$ values) were obtained to assess interactions between BP, weight, age and measurements of cardiovascular injury. Multivariate analysis was used to examine the independent contributions of relative weight, age and posterior wall thickness to peak filling rate. All $p$ values $<0.05$ were accepted as the level at which the null hypothesis was rejected.

\section{RESULTS}

Descriptive data for the hypertensive and normotensive groups are listed in Table I. The results indicate that the 2 groups were statistically similar for age, height, weight and relative weight. Based on the selection process, the hypertensive group had significantly higher BP values both in the clinic and at home.

The indexes of cardiovascular injury are listed in Table II. The 2 groups had statistically indistinguishable values for minimal forearm vascular resistance, ventricular septal and posterior wall thickness, LV muscle mass and diastolic peak filling rate.

The relations of $B P$, relative weight and age to the various measures of cardiovascular change are listed in Table III. Because home BPs did not provide stronger correlation coefficients than clinic BPs with the various measures of cardiovascular change, only the latter are reported. As listed in Table III, relative weight, posterior wall thickness and age were significant correlates of

\begin{tabular}{|c|c|c|c|}
\hline & $\begin{array}{l}\text { Normotensive } \\
(n=13)\end{array}$ & $\begin{array}{l}\text { Hypertensive } \\
(n=18)\end{array}$ & p Value \\
\hline Age (yrs) & $37 \pm 2$ & $36 \pm 2$ & NS \\
\hline Height (cm) & $179 \pm 2$ & $182 \pm 1$ & NS \\
\hline Weight (kg) & $87 \pm 4$ & $92 \pm 4$ & NS \\
\hline MRW (\%) & $125 \pm 7$ & $128 \pm 3$ & NS \\
\hline $\begin{array}{l}\text { Sytolic BP (clinic) } \\
(\mathrm{mm} \mathrm{Hg})\end{array}$ & $121 \pm 4$ & $137 \pm 3$ & $<0.001$ \\
\hline $\begin{array}{l}\text { Diastolic BP (clinic) } \\
(\mathrm{mm} \mathrm{Hg})\end{array}$ & $81 \pm 3$ & $96 \pm 2$ & $<0.001$ \\
\hline $\begin{array}{l}\text { Systolic BP (home) } \\
\text { (mm Hg) }\end{array}$ & $119 \pm 3$ & $137 \pm 2$ & $<0.001$ \\
\hline $\begin{array}{l}\text { Diastolic BP (home) } \\
(\mathrm{mm} \mathrm{Hg})\end{array}$ & $75 \pm 2$ & $91 \pm 2$ & $<0.001$ \\
\hline
\end{tabular}

\begin{tabular}{|c|c|c|c|}
\hline & $\begin{array}{l}\text { Normotensive } \\
(n=13)\end{array}$ & $\begin{array}{l}\text { Hypertensive } \\
(n=19)\end{array}$ & $p$ Value \\
\hline $\begin{array}{l}\text { Minimum vascular } \\
\text { resistance (U) }\end{array}$ & $2.03 \pm 0.11$ & $2.20 \pm 0.11$ & NS \\
\hline Septal thickness (mm) & $10.2 \pm 0.3$ & $9.9 \pm 0.4$ & NS \\
\hline Posterior wall (mm) & $10.0 \pm 0.3$ & $10.2 \pm 0.4$ & NS \\
\hline LV muscle mass (g) & $223 \pm 16$ & $227 \pm 14$ & NS \\
\hline LV mass index $\left(\mathrm{g} / \mathrm{m}^{2}\right)$ & $107 \pm 6$ & $106 \pm 6$ & NS \\
\hline Peak filling rate (liters/s) & $2.69 \pm 0.07$ & $2.71 \pm 0.14$ & NS \\
\hline
\end{tabular}

\begin{tabular}{|c|c|c|c|c|c|c|}
\hline & $\begin{array}{l}\text { PFR } \\
\text { (liters/s) }\end{array}$ & $\begin{array}{l}\text { IVS } \\
(\mathrm{mm})\end{array}$ & $\begin{array}{l}P W \\
(\mathrm{~mm})\end{array}$ & $\begin{array}{l}\text { LVMM } \\
\text { (g) }\end{array}$ & $\begin{array}{l}\text { LVMI } \\
\left(\mathrm{g} / \mathrm{m}^{2}\right)\end{array}$ & $\begin{array}{l}\text { MFAVR } \\
\text { (U) }\end{array}$ \\
\hline $\begin{array}{l}\text { Systolic BP } \\
\text { (clinic) }\end{array}$ & 0.02 & $0.44^{\dagger}$ & $0.45^{\dagger}$ & 0.29 & 0.25 & 0.28 \\
\hline $\begin{array}{c}\text { Diastolic BP } \\
\text { (clinic) }\end{array}$ & -0.02 & $0.35^{\dagger}$ & 0.29 & 0.26 & 0.22 & 0.26 \\
\hline Relative weight & $-0.62^{\ddagger}$ & $0.47^{\ddagger}$ & $0.59 \ddagger$ & $0.54^{\ddagger}$ & $0.38^{\dagger}$ & 0.19 \\
\hline Age & $-0.45^{\dagger}$ & 0.23 & 0.22 & 0.14 & 0.08 & $0.35^{\dagger}$ \\
\hline
\end{tabular}

peak filling rate, an index of diastolic function. Relative weight (partial $\mathrm{r}=-0.47$ ) and age (partial $\mathrm{r}=-0.36$ ) retained a significant $(\mathrm{p}<0.05)$ independent relation to peak filling rate in multivariate analysis, while the relation to posterior wall disappeared (partial $\mathrm{r}=-0.18$, difference not significant). The significant negative correlation between relative weight and peak filling rate is shown in Figure 1.

\section{DISCussion}

The data listed in Table I indicate that the 2 groups had similar values for age, height, weight and relative weight. Despite higher clinic and home BP levels, the hypertensive group, in comparison with normotensive subjects, did not have significantly different values for maximal vasodilator capacity, septal or posterior wall 
thickness, LV muscle mass or mass index, or peak diastolic filling rate as listed in Table II.

Minimal forearm vascular resistance: The vascular resistance persisting after 10 minutes of ischemic forearm exercise is a measure of structural arteriolar crosssectional area.,7 Several investigators observed elevated values for minimal vascular resistance in patients with borderline and mild hypertension compared with normotensive control subjects. ${ }^{6,7}$ Although the mean minimal forearm resistance was higher in the hypertensive group, the difference was not significant. In 1 of our previous studies, ${ }^{7}$ hypertensive patients, compared with age- and weight-matched normotensive control subjects, had significantly higher minimal forearm vascular resistance. In the largest study, ${ }^{6} \mathrm{BP}$ was a significant, albeit relatively weak $\left(\mathrm{r}^{2}=0.16\right)$ determinant of minimal forearm vascular resistance. Thus, the dichotomy of the minimal resistance results in our 2 studies may be explained by smaller mean BP differences between hypertensives and normotensives in the present investigation.

Left ventricular wall thickness and muscle mass: Abnormally high values for ventricular septal and posterior wall thickness as well as LV muscle mass in subjects with borderline and mild hypertension are well documented. ${ }^{20-22}$ The increased LV wall thickness and mass also are found in children and adolescents with minimal abnormalities of BP. ${ }^{21,22}$ Although posterior wall and ventricular septal thickness correlated significantly with clinic systolic BP as listed in Table III, neither posterior wall or ventricular septal thickness nor LV muscle mass was significantly elevated in hypertensive patients (Table II). This finding is at variance with many published studies. Relative weight correlated significantly with posterior wall, ventricular septal, LV muscle mass and mass index. Thus, our deliberate weight matching of hypertensive patients and normotensive control subjects may have obliterated the influ- ence of very mild hypertension on ventricular morphology.

This conclusion is consistent with the observations by Messerli et al, ${ }^{23}$ who indicated that both overweight and hypertension increase LV wall thickness. LV wall thickness was higher in lean hypertensive versus lean normotensive persons. However, posterior and septal wall thickness were not significantly increased in overweight hypertensive patients compared with overweight normotensive control subjects. Consequently, weight was more important than BP in determining cardiac structure in obese patients with mild hypertension. ${ }^{23}$

Left ventricular diastolic function: In this study, peak LV filling rate at rest assessed by radionuclide ventriculography served as the measure of cardiac diastolic function. Our data show that the peak filling rate was virtually identical in hypertensive patients compared with normotensive control subjects of similar age and weight. These findings are in direct contrast to several previous studies in which evidence was found of reduced ventricular diastolic function in untreated patients with mild hypertension. ${ }^{8-12}$ The majority of studies did not report values for weight in either the hypertensive patients or normotensive control subjects. ${ }^{8-}$ 11 The weight data reported in 1 study indicated that the group with higher BP also had higher mean weight values. ${ }^{14}$ The potential importance of weight in determining diastolic function was suggested in 1981 by DeDevitis et al. ${ }^{24}$ This group observed a significantly positive correlation between overweight and both $\mathrm{LV}$ enddiastolic pressure and amplitude of the $\mathrm{A}$ waves in the pulmonary wedge pressure tracing in obese normotensive men. Our findings, listed in Table III and shown in Figure 1, confirm that overweight is associated with impaired diastolic function. The study was not designed to determine the physiologic basis for this association. The data extend previous findings by showing that over-

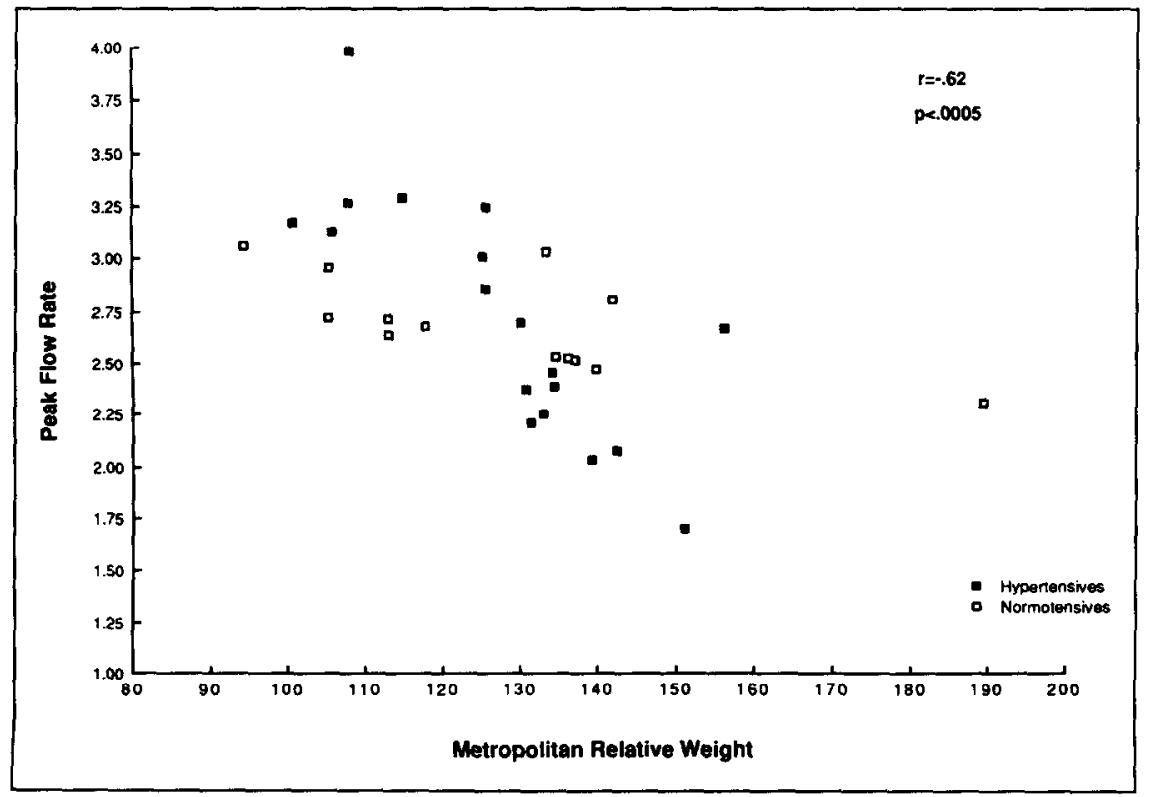

FIGURE 1. The significantly negative relation between data obtained from the Metropolitan Life Insurance Co. Relative Welght values and LV peak diastolic fiow rate (thers/s) is shown for hypertendive patients (closed squares) and normolentive subjects (open squares). 
weight predominates over very mild elevations of BP in determining diastolic function. This conclusion is further substantiated by multivariate analysis, which indicates that relative weight is the single best predictor of peak filling rate.

After relative weight, age was the only other variable significantly and independently correlated with diastolic function. These data are consistent with the observations of Spirito and Maron, ${ }^{25}$ who reported that $\mathrm{LV}$ relaxation is impaired with aging. Although posterior wall thickness correlated with diastolic function, the relation was insignificant in multivariate analysis when accounting for the effects of relative weight and age. A brief review of published studies also suggests a complex and somewhat variable relation between $\mathrm{LV}$ anatomy and cardiac diastolic function. Some studies found that ventricular wall thickness and LV muscle mass were the main correlates of diastolic function. ${ }^{26,27}$ However, trained athletes with various degrees of LV hypertrophy observed in pathologic states had supranormal diastolic function. ${ }^{28}$ Thus, the influence of LV hypertrophy on diastolic function must be interpreted in the context of factors inducing the morphologic change. Furthermore, abnormalities of diastolic function in hypertension may exist in the absence of increased LV wall thickness or muscle mass. ${ }^{8,10,12}$ In these cases, disordered cellular calcium metabolism, perhaps an integral feature of hypertension, ${ }^{29}$ may contribute to reduced diastolic function independently of structural changes. ${ }^{30}$

\section{REFERENCES}

1. Medical Research Council Working Party. MRC trial of treatment of mild hypertension: principal results. Br Med J 1985:291:97-104

2. Smith DE, Odel HM, Kernohan JW. Causes of death in hypertension. Am J Med 1950,9:516-527.

3. Kannel WB, Gordon T, Castelli WP, Margolis JR. Electrocardiographic left ventricular hypertrophy and risk of coronary heart disease. Ann Intern Med 1970:72:813-822.

4. Levy D, Andersun KM, Savage DD, Balkus SA, Kannel WB, Castelli WP.

Risk of ventricular arrhythmias in left ventricular hypertrophy: the Framingham

Heart Study. Am J Cardiol 1987,60:560-565.

5. Casale PN, Devereux RV, Milner M, Zullo G, Harshfield GA, Pickering TG, Laragh JH. Value of echocardiographic measurement of left ventricular mass in predicting cardiovascular morbid events in hypertensive men. Ann Intern Med 1986:105:173-178.

6. Conway J. A vascular abnormality in hypertension. A study of blood flow in the forearm. Circulation 1963;27:520-529.

7. Egan B, Schork N, Panis R, Hinderliter A. Vascular structure enhances resistance responses in mild essential hypertension. $J$ Hypertens 1988,6:4I-48. 8. Hartford M, Wilkstrand J, Wallentin I, Ljungnau S. Wilhelnison L, Berglund G. Diastolic function of the heart in untreated primary hypertension. Hypertension 1984,6:329-338.

9. Inouye I, Massie B, Loge D, Topic N, Silverstein D, Simpson P, Tubau J. Abnormal left ventricular filling: an early finding in mild to moderate systemic hypertension. Am J Cardiol 1985;53:120 -126.

10. Dianzumba SB, DiPette DJ, Cornman C, Weber E, Joyner CR. Left ventricular filling characteristics in mild untreated hypertension. Hypertension 1986; 8(suppl):II56-1160.

11. Fouad FM, Tarazi RC, Gallagher JH, Macintyre WJ, Cook SA. Abnormal left ventricular relaxation in hypertensive patients. Clin Sci 1980;59:411S-414S. 12. Snider AR, Gidding SS, Rocchini AP, Rosenthal A, Dick M, Crowley DC Peters J. Doppler evaluation of left ventricular diastolic filling in children with systemic hypertension. Am J Cardiol 1985:56:921-926.

13. Kannel WB, Brand N, Skinner JJ, Dauber TR, McNamara PM. The relationship of adiposity to blood pressure and development of hypertension. The Framingham Study. Ann Intern Med 1967,67:48-59.

14. Hubert HB, Feinleib M, McNamara PM, Castelli WP. Obesity as an independent risk factor for cardiovascular disease: a 26-year follow-up of participants in the Framingham Heart Study. Circulation 1983,67:968-977.

15. Messerli FH. Obesity in hypertension: how innocent a bystander? Am J Med 1984:77:1077-1082

16. Keys A, Fidanza F, Karvonen MJ, Kimura N, Taylor HL. Indices of relative wcight and obesity. J Chronic Dis 1972;25:329-343.

17. Sahn DJ, DeMaria A, Kisslo J, Weyman A. Recommendations regarding quantitation in M-mode echocardiography; results of a survey of echocardiographic measurements. Circulation 1978;58:1072-1081

18. Devereux RB, Reichek N. Echocardiographic determination of left ventricular mass in man. Circulation 1977.55:613-618.

19. Juni JE, Chen CC. Effects of gating modes on the analysis of left ventricular function in the presence of heart rate variation. $J$ Nucl Med 1988;29:1272-1278. 20. Savage DD, Drayer JIM, Henry WL, Matthews EC, Ware JH, Gardin JM, Cohen ER, Epstein SE, Laragh JH. Echocardiographic assessment of cardiac anatomy and function in hypertensive subjects. Circulation 1979;59:623-632. 21. Culpepper WS, Sodt PC, Messerli FH, Ruschhaupt DG, Arcilla RA. Cardiac status in juvenile borderline hypertension. Ann Intern Med 1983,98:1-7.

22. Schieken RM, Clarke WR, Lauer RM. Left ventricular hypertrophy in children with blood pressures in the upper quintile of the distribution. The Muscatine Study. Hypertension 1981;3.669-675.

23. Messerli FH, Sundgaard-Riise K, Reisen ED, Draslinski GR, Ventura HO Oigman W, Frohlich ED, Dunn FG. Dimorphic cardiac adaptation to obesity and arterial hypertension. Ann Intern Med 1983,99:757-761.

24. DeDivitis O, Fazio S, Pettito M, Maddalena G, Contaldo F, Mancini M. Obesity and cardiac function. Circulation 1981,64:477-482.

25. Spirito $P$, Maron BJ. Influence of aging on Doppler echocardiographic indices of left ventricular function. Br Heart $J$ 1988;59:672-679.

26. Fouad FM, Slominski M, Tarazi RC. Left ventricular diastolic function in hypertension: relation to left ventricular mass and systolic function. $J A C C$ 1984:3:1500-1506.

27. Shapiro LM, McKenna WJ. Left ventricular hypertrophy: relation of structure to diastolic function in hypertension. Br Heart J 1984;51:637-642.

28. Colan SD, Sanders SP, MacPherson D, Borow KM Left ventricular diastolic function in elite athletes with physiologic cardiac hypertrophy. JACC 1985,6:545549.

29. Erne P, Bolli P, Burgisser E, Buhler FR. Correlation of platelet calcium with blood pressure. Effect of antihypertensive therapy. N Engl J Med 1984:310:10841088

30. Nayler WG, Williams A. Relaxation in heart muscle: some morphological and biochemical considerations. Eur J Cardiol 1978;7(suppl):35-50. 